\title{
Strong convergence for total quasi- $\phi$-asymptotically nonexpansive semigroups in Banach spaces
}

\author{
Jing Quan ${ }^{1 *}$, Shih-sen Chang ${ }^{2}$ and Xiongrui Wang ${ }^{1}$
}

"Correspondence:

quanjingcq@163.com

'Department of Mathematics, Yibin

University, Yibin, Sichuan, 644000,

China

Full list of author information is

available at the end of the article

\begin{abstract}
The purpose of this article is to use the modified Halpern-Mann type iteration algorithm for total quasi- $\phi$-asymptotically nonexpansive semigroups to prove strong convergence in Banach spaces. The main results presented in this paper extend and improve the corresponding results of many authors.
\end{abstract}

MSC: 47H05; 47H09; 49M05

Keywords: strong convergence; total quasi- $\phi$-asymptotically nonexpansive semigroups; generalized projection

\section{Introduction}

Throughout this article, we assume that $E$ is a real Banach space with norm $\|\cdot\|, E^{*}$ is the dual space of $E ;\langle\cdot, \cdot\rangle$ is the duality pairing between $E$ and $E^{*} ; C$ is a nonempty closed convex subset of $E ; \mathbb{N}$ and $\mathbb{R}$ denote the natural number set and the set of nonnegative real numbers respectively. The mapping $J: E \rightarrow 2^{E^{*}}$ defined by

$$
J(x)=\left\{f^{*} \in E^{*}:\left\langle x, f^{*}\right\rangle=\|x\|^{2} ;\left\|f^{*}\right\|=\|x\|, x \in E\right\}
$$

is called the normalized duality mapping. Let $T: C \rightarrow C$ be a nonlinear mapping; $F(T)$ denotes the set of fixed points of mapping $T$.

Alber et al. [1] introduced a more general class of asymptotically nonexpansive mappings called total asymptotically nonexpansive mappings and studied the methods of approximation of fixed points. They are defined as follows.

Definition 1.1 Let $T: C \rightarrow C$ be a mapping. $T$ is said to be total asymptotically nonexpansive if there exist sequences $\left\{\mu_{n}\right\},\left\{v_{n}\right\}$ with $\mu_{n}, v_{n} \rightarrow 0$ as $n \rightarrow \infty$ and a strictly increasing continuous function $\psi: \mathbb{R} \rightarrow \mathbb{R}$ with $\psi(0)=0$ such that $\left\|T^{n} x-T^{n} y\right\| \leq$ $\|x-y\|+\mu_{n} \psi(\|x-y\|)+v_{n}$ holds for all $x, y \in C$ and all $n \in \mathbb{N}$.

$T$ is said to be total asymptotically quasi-nonexpansive if $F(T) \neq \emptyset$, there exist sequences $\left\{\mu_{n}\right\},\left\{v_{n}\right\}$ with $\mu_{n}, v_{n} \rightarrow 0$ as $n \rightarrow \infty$ and a strictly increasing continuous function $\psi: \mathbb{R} \rightarrow$ $\mathbb{R}$ with $\psi(0)=0$ such that $\left\|T^{n} x-p\right\| \leq\|x-p\|+\mu_{n} \psi(\|x-p\|)+v_{n}$ holds for all $x \in C$, $p \in F(T)$ and all $n \in \mathbb{N}$.

Chidume and Ofoedu [2] introduced an iterative scheme for approximation of a common fixed point of a finite family of total asymptotically nonexpansive mappings and

C 2012 Quan et al.; licensee Springer. This is an Open Access article distributed under the terms of the Creative Commons Attribution License (http://creativecommons.org/licenses/by/2.0), which permits unrestricted use, distribution, and reproduction in any medium, provided the original work is properly cited. 
total asymptotically quasi-nonexpansive mappings in Banach spaces. Chidume et al. [3] gave a new iterative sequence and necessary and sufficient conditions for this sequence to converge to a common fixed point of finite total asymptotically nonexpansive mappings. Chang [4] established some new approximation theorems of common fixed points for a countable family of total asymptotically nonexpansive mappings in Banach spaces.

Recently, many researchers have focused on studying the convergence of iterative algorithms for quasi- $\phi$-asymptotically nonexpansive (see [5-9]) and total quasi- $\phi$-asymptotically nonexpansive (see [10-12]) mappings. Ye et al. [13] used a new hybrid projection algorithm to obtain strong convergence theorems for fixed point problems and generalized equilibrium problems of three relatively quasi-nonexpansive mappings in Banach spaces. Kim [14] used hybrid projection methods for equilibrium problems and fixed point problems of the asymptotically quasi- $\phi$-nonexpansive mappings to prove the strong convergence theorems. Saewan [15] used the shrinking projection method for solving generalized equilibrium problems and common fixed points for asymptotically quasi- $\phi$-nonexpansive mappings.

A Banach space $E$ is said to be strictly convex if $\frac{\|x+y\|}{2}<1$ for $\|x\|=\|y\|=1$ and $x \neq y$; it is also said to be uniformly convex if $\lim _{n \rightarrow \infty}\left\|x_{n}-y_{n}\right\|=0$ for any two sequences $\left\{x_{n}\right\},\left\{y_{n}\right\}$ in $E$ such that $\left\|x_{n}\right\|=\left\|y_{n}\right\|=1$ and $\lim _{n \rightarrow \infty} \frac{\left\|x_{n}+y_{n}\right\|}{2}=1$. Let $U=\{x \in E:\|x\|=1\}$ be the unit sphere of $E$, then the Banach space $E$ is said to be smooth provided $\lim _{t \rightarrow 0} \frac{\|x+t y\|-\|y\|}{t}$ exists for each $x, y \in U$. It is also said to be uniformly smooth if the limit is attained uniformly for each $x, y \in U$. It is well known that if $E$ is reflexive and smooth, then the duality mapping $J$ is single valued. A Banach space $E$ is said to have the Kadec-Klee property if a sequence $\left\{x_{n}\right\}$ of $E$ satisfies that $x_{n} \rightarrow x \in E$ and $\left\|x_{n}\right\| \rightarrow x$, then $x_{n} \rightarrow x$. It is known that if $E$ is uniformly convex, then $E$ has the Kadec-Klee property.

In the sequel, we assume that $E$ is a smooth, strictly convex and reflexive Banach space and $C$ is a nonempty closed convex subset of $E$. We use $\phi: E \times E \rightarrow R^{+}$to denote the Lyapunov functional defined by

$$
\phi(x, y)=\|x\|^{2}-2\langle x, J y\rangle+\|y\|^{2}, \quad \forall x, y \in E .
$$

It is obvious that

$$
(\|x\|-\|y\|)^{2} \leq \phi(x, y) \leq(\|x\|+\|y\|)^{2}, \quad \forall x, y \in E,
$$

and

$$
\phi\left(x, J^{-1}(\lambda J y+(1-\lambda) J z)\right) \leq \lambda \phi(x, y)+(1-\lambda) \phi(x, z) .
$$

Following Alber [16], the generalized projection $\Pi_{C} x: E \rightarrow C$ is defined by

$$
\Pi_{C} x=\arg \inf _{y \in C} \phi(y, x), \quad \forall x \in E .
$$

The quasi- $\phi$-asymptotically nonexpansive and total quasi- $\phi$-asymptotically nonexpansive mappings are defined as follows. 
Definition 1.2 A mapping $T: C \rightarrow C$ is said to be quasi- $\phi$-asymptotically nonexpansive, if $F(T) \neq \emptyset$, there exist sequences $\left\{k_{n}\right\} \subset[1,+\infty)$ with $k_{n} \rightarrow 1$ as $n \rightarrow \infty$ such that

$$
\phi\left(p, T^{n} x\right) \leq k_{n} \phi(p, x)
$$

holds for all $x \in C, p \in F(T)$ and all $n \in \mathbb{N}$.

A mapping $T: C \rightarrow C$ is said to be total quasi- $\phi$-asymptotically nonexpansive, if $F(T) \neq$ $\emptyset$, there exist sequences $\left\{\mu_{n}\right\},\left\{v_{n}\right\}$ with $\mu_{n}, v_{n} \rightarrow 0$ as $n \rightarrow \infty$ and a strictly increasing continuous function $\psi: \mathbb{R} \rightarrow \mathbb{R}$ with $\psi(0)=0$ such that

$$
\phi\left(p, T^{n} x\right) \leq \phi(p, x)+\mu_{n} \psi(\phi(p, x))+v_{n}
$$

holds for all $x \in C, p \in F(T)$ and all $n \in \mathbb{N}$.

In recent years, many researchers have considered the convergence of asymptotically nonexpansive semigroups $[17,18]$. The asymptotically nonexpansive semigroups are defined as follows.

Definition 1.3 [17] One-parameter family $\mathbf{T}:=\{T(t): t \geq 0\}$ of mappings from $C$ into itself is said to be an asymptotically nonexpansive semigroup on $C$, if the following conditions are satisfied:

(a) $T(0) x=x$ for each $x \in C$;

(b) $T(t+s) x=T(s) T(t)$ for any $t, s \in R^{+}$and $x \in C$;

(c) For any $x \in C$, the mapping $t \rightarrow T(t) x$ is continuous;

(d) There exist sequences $\left\{k_{n}\right\} \subset[1,+\infty)$ with $k_{n} \rightarrow 1$ as $n \rightarrow \infty$ such that

$$
\left\|T^{n}(t) x-T^{n}(t) y\right\| \leq k_{n}\|x-y\|
$$

holds for all $x, y \in C, n \in \mathbb{N}$.

We use $F(T)$ to denote the common fixed point set of the semigroup T, i.e., $F(T)=$ $\bigcap_{t \geq 0} F(T(t))$.

Chang [19] used the modified Halpern-Mann type iteration algorithm for quasi- $\phi$ asymptotically nonexpansive semigroups to prove the strong convergence in the Banach space. The quasi- $\phi$-asymptotically nonexpansive semigroups are defined as follows.

Definition 1.4 [19] One-parameter family $\mathbf{T}:=\{T(t): t \geq 0\}$ of mappings from $C$ into itself is said to be a quasi- $\phi$-asymptotically nonexpansive semigroup on $C$ if the conditions (a), (b), (c) in Definition 1.3 and following condition (e) are satisfied:

(e) For all $x, y \in C, p \in F((T)), t \geq 0$, there exist sequences $\left\{k_{n}\right\} \subset[1,+\infty)$ with $k_{n} \rightarrow 1$ as $n \rightarrow \infty$, such that

$$
\phi\left(p, T^{n}(t) x\right) \leq k_{n} \phi(p, x)
$$

holds for all $n \in \mathbb{N}$. 


\section{Preliminaries}

This section contains some definitions and lemmas which will be used in the proofs of our main results in the following section.

Definition 2.1 One-parameter family $\mathbf{T}:=\{T(t): t \geq 0\}$ of mappings from $C$ into itself is said to be a total quasi- $\phi$-asymptotically nonexpansive semigroup on $C$ if conditions (a), (b), (c) in Definition 1.3 and following condition (f) are satisfied:

(f) If $F(T) \neq \emptyset$, there exist sequences $\left\{\mu_{n}\right\},\left\{v_{n}\right\}$ with $\mu_{n}, v_{n} \rightarrow 0$ as $n \rightarrow \infty$ and a strictly increasing continuous function $\psi: \mathbb{R} \rightarrow \mathbb{R}$ with $\psi(0)=0$ such that

$$
\phi\left(p, T^{n}(t) x\right) \leq \phi(p, x)+\mu_{n} \psi(\phi(p, x))+v_{n}
$$

holds for all $x \in C, p \in F(T)$ and all $n \in \mathbb{N}$.

A total quasi- $\phi$-asymptotically nonexpansive semigroup $\mathbf{T}$ is said to be uniformly Lipschitzian if there exists a bounded measurable function $L:[0, \infty) \rightarrow(0,+\infty)$ such that

$$
\left\|T^{(n)}(t) x-T^{(n)}(t) y\right\| \leq L(t)\|x-y\|, \quad \forall x, y \in C, t \geq 0, n \in \mathbb{N} .
$$

The purpose of this article is to use the modified Halpern-Mann type iteration algorithm for total quasi- $\phi$-nonexpansive asymptotically semigroups to prove the strong convergence in Banach spaces. The results presented in the article improve and extend the corresponding results of $[5,6,9-12,14,15,19]$ and many others.

In order to prove the results of this paper, we shall need the following lemmas:

Lemma 2.1 (See [16]) Let E be a smooth, strictly convex and reflexive Banach space and $C$ be a nonempty closed convex subset of $E$. Then the following conclusions hold:

(i) $\phi\left(x, \Pi_{C} y\right)+\phi\left(\Pi_{C} y, y\right) \leq \phi(x, y)$ for all $x \in C, y \in E$;

(ii) If $x \in E$ and $z \in C$, then $z=\Pi_{C} x \Leftrightarrow\langle z-y, J x-J z\rangle \geq 0, \forall y \in C$;

(iii) For $x, y \in E, \phi(x, y)=0$ if and only if $x=y$.

Lemma 2.2 [19] Let E be a uniformly convex and smooth Banach space and let $\left\{x_{n}\right\}$ and $\left\{y_{n}\right\}$ be two sequences of $E$. If $\phi\left(x_{n}, y_{n}\right) \rightarrow 0$ and either $\left\{x_{n}\right\}$ or $\left\{y_{n}\right\}$ is bounded, then $\| x_{n}-$ $y_{n} \| \rightarrow 0$.

Lemma 2.3 [10] Let E be a real uniformly smooth and strictly convex Banach space with the Kadec-Klee property, and C be a nonempty closed convex subset of E. Let $T: C \rightarrow C$ be a closed and total quasi- $\phi$-asymptotically nonexpansive mapping defined by Definition 1.2. If $v_{1}=0$, then the fixed point set $F(T)$ of $T$ is a closed and convex subset of $C$.

\section{Main results}

Theorem 3.1 Let E be a real uniformly convex and uniformly smooth Banach space and $C$ be a nonempty closed convex subset of $E$. Let $\mathbf{T}:=\{T(t): t \geq 0\}$ be a total quasi- $\phi$ asymptotically nonexpansive semigroup from $C$ into itself defined by Definition 2.1. Suppose $\mathbf{T}:=\{T(t): t \geq 0\}$ is closed, uniformly L-Lipschitz and $F(T):=\bigcap_{t \geq 0} F(T(t)) \neq \emptyset$. Suppose there exists $M^{*}>0$ such that $\psi\left(\eta_{n}\right) \leq M^{*} \eta_{n}$. Let $\alpha_{n}$ be a sequence in $[0,1]$ and $\beta_{n}$ be 
a sequence in $(0,1)$ satisfying the following conditions: $\lim _{n \rightarrow \infty} \alpha_{n}=0,0<\liminf _{n \rightarrow \infty} \beta_{n}<$ $\limsup _{n \rightarrow \infty} \beta_{n}<1$. Let $x_{n}$ be a sequence generated by

$$
\left\{\begin{array}{l}
x_{1} \in E, \quad \text { chosen arbitrarily; } \quad C_{1}=C, \\
l_{n, t}=\beta_{n} J x_{n}+\left(1-\beta_{n}\right) J T^{n}(t) x_{n}, \\
y_{n, t}=J^{-1}\left[\alpha_{n} J x_{1}+\left(1-\alpha_{n}\right) l_{n, t}\right], \quad t \geq 0, \\
C_{n+1}=\left\{z \in C_{n}: \sup _{t \geq 0} \phi\left(z, y_{n, t}\right) \leq \alpha_{n} \phi\left(z, x_{1}\right)+\left(1-\alpha_{n}\right) \phi\left(z, x_{n}\right)+\xi_{n}\right\}, \\
x_{n+1}=\Pi_{C_{n+1}} x_{1}, \quad \forall n \geq 1,
\end{array}\right.
$$

where $\xi_{n}=\mu_{n} M^{*} \sup _{p \in F(T)} \phi\left(p, x_{n}\right)$. If $v_{1}=0$ and $F(T)$ is bounded in $C$, then the iterative sequence $\left\{x_{n}\right\}$ converges strongly to a common fixed point $x^{*} \in F(T)$ in $C$.

\section{Proof}

(I) We prove $F(T)$ and $C_{n}(n \in \mathbb{N})$ all are closed and convex subsets in $C$.

It follows from Lemma 2.3 that $F(T(t)), t \geq 0$ is a closed and convex subset of $C$. So $F(T)$ is closed and convex in $C$. By the assumption we know that $C_{1}=C$ is closed and convex. We suppose that $C_{n}$ is closed and convex for some $n \geq 2$. By the definition of $\phi$, we have that

$$
\begin{aligned}
C_{n+1}= & \left\{z \in C_{n}: \sup _{t \geq 0} \phi\left(z, y_{n, t}\right) \leq \alpha_{n} \phi\left(z, x_{1}\right)+\left(1-\alpha_{n}\right) \phi\left(z, x_{n}\right)+\xi_{n}\right\} \\
= & \bigcap_{t \geq 0}\left\{z \in C: \phi\left(z, y_{n, t}\right) \leq \alpha_{n} \phi\left(z, x_{1}\right)+\left(1-\alpha_{n}\right) \phi\left(z, x_{n}\right)+\xi_{n}\right\} \cap C_{n} \\
= & \bigcap_{t \geq 0}\left\{z \in C: 2 \alpha_{n}\left\langle z, J x_{1}\right\rangle+2\left(1-\alpha_{n}\right)\left\langle z, J x_{n}\right\rangle-2\left\langle z, J y_{n, t}\right\rangle\right. \\
& \left.\leq \alpha_{n}\left\|x_{1}\right\|^{2}+\left(1-\alpha_{n}\right)\left\|x_{n}\right\|^{2}-\left\|y_{n, t}\right\|^{2}\right\} \cap C_{n} .
\end{aligned}
$$

This shows that $C_{n+1}$ is closed and convex.

(II) We prove that $F(T) \subset C_{n}$.

In fact $F(T) \subset C_{1}=C$. Suppose that $F(T) \subset C_{n}, n \geq 2$. Let

$$
\omega_{n, t}=J^{-1}\left(\beta_{n} J x_{n}+\left(1-\beta_{n}\right) J T^{n}(t) x_{n}\right), \quad t \geq 0 .
$$

It follows from (2) that for any $u \in F(T) \subset C_{n}$, we have

$$
\begin{aligned}
\phi\left(u, y_{n, t}\right) & =\phi\left(u, J^{-1}\left(\alpha_{n} J x_{1}+\left(1-\alpha_{n}\right) J \omega_{n, t}\right)\right) \\
& \leq \alpha_{n} \phi\left(u, x_{1}\right)+\left(1-\alpha_{n}\right) \phi\left(u, \omega_{n, t}\right),
\end{aligned}
$$

and

$$
\begin{aligned}
\phi\left(u, \omega_{n, t}\right) & =\phi\left(u, J^{-1}\left(\beta_{n} J x_{n}+\left(1-\beta_{n}\right) J T^{n}(t) x_{n}\right)\right) \\
& \leq \beta_{n} \phi\left(u, x_{n}\right)+\left(1-\beta_{n}\right) \phi\left(u, T^{n}(t) x_{n}\right) \\
& \leq \beta_{n} \phi\left(u, x_{n}\right)+\left(1-\beta_{n}\right)\left[\phi\left(u, x_{n}\right)+\mu_{n} \psi\left(\phi\left(u, x_{n}\right)\right)+v_{n}\right] \\
& \leq \phi\left(u, x_{n}\right)+\left(1-\beta_{n}\right)\left(\mu_{n} M^{*} \phi\left(u, x_{n}\right)+v_{n}\right) .
\end{aligned}
$$


Therefore, we have

$$
\begin{aligned}
\sup _{t \geq 0} \phi\left(u, y_{n, t}\right) & \leq \alpha_{n} \phi\left(u, x_{1}\right)+\left(1-\alpha_{n}\right)\left[\phi\left(u, x_{n}\right)+\left(1-\beta_{n}\right)\left(\mu_{n} M^{*} \phi\left(u, x_{n}\right)+v_{n}\right)\right] \\
& \leq \alpha_{n} \phi\left(u, x_{1}\right)+\left(1-\alpha_{n}\right) \phi\left(u, x_{n}\right)+\mu_{n} M^{*} \sup _{p \in F(T)} \phi\left(p, x_{n}\right)+v_{n} \\
& =\alpha_{n} \phi\left(u, x_{1}\right)+\left(1-\alpha_{n}\right) \phi\left(u, x_{n}\right)+\xi_{n} .
\end{aligned}
$$

Where $\xi_{n}=\mu_{n} M^{*} \sup _{p \in F(T)} \phi\left(p, x_{n}\right)+v_{n}$. This shows that $u \in C_{n+1}$, so $F(T) \subset C_{n+1}$.

(III) We prove that $\left\{x_{n}\right\}$ is a Cauchy sequence in $C$.

Since $x_{n}=\Pi_{C_{n}} x_{1}$, from Lemma 2.1(ii), we have

$$
\left\langle x_{n}-y, J x_{1}-J x_{n}\right\rangle \geq 0, \quad \forall y \in C_{n} .
$$

Again since $F(T) \subset C_{n}, n \geq 1$, we have

$$
\left\langle x_{n}-u, J x_{1}-J x_{n}\right\rangle \geq 0, \quad \forall u \in F(T) .
$$

It follows from Lemma 2.1(i) that for each $u \in F(T), n \geq 1$,

$$
\phi\left(x_{n}, x_{1}\right)=\phi\left(\Pi_{C_{n}} x_{1}, x_{1}\right) \leq \phi\left(u, x_{1}\right)-\phi\left(u, x_{n}\right) \leq \phi\left(u, x_{1}\right) .
$$

Therefore, $\phi\left(x_{n}, x_{1}\right)$ is bounded. By virtue of (1), $x_{n}$ is also bounded. Since $x_{n}=\Pi_{C_{n}} x_{1}$ and $x_{n+1}=\Pi_{C_{n+1}} x_{1} \in C_{n+1} \subset C_{n}$, we have $\phi\left(x_{n}, x_{1}\right) \leq \phi\left(x_{n+1}, x_{1}\right)$. This implies that $\left\{\phi\left(x_{n}, x_{1}\right)\right\}$ is

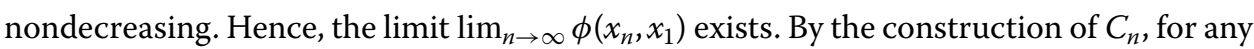
positive integer $m \geq n$, we have $C_{m} \subset C_{n}$ and $x_{m}=\Pi_{C_{1}} x_{1} \in C_{n}$. This shows that

$$
\begin{aligned}
\phi\left(x_{m}, x_{n}\right) & =\phi\left(x_{m}, \Pi_{C_{n}} x_{1}\right) \\
& \leq \phi\left(x_{m}, x_{1}\right)-\phi\left(x_{n}, x_{1}\right) \rightarrow 0, \quad \text { as } m, n \rightarrow \infty .
\end{aligned}
$$

It follows from Lemma 2.2 that $\lim _{n, m \rightarrow \infty}\left\|x_{m}-x_{n}\right\|=0$. Hence $x_{n}$ is a Cauchy sequence in $C$. Since $C$ is complete, without loss of generality, we can assume that $x_{n} \rightarrow p^{*}$ (some point in $C$ ). By the assumption, we have that

$$
\lim _{n \rightarrow \infty} \xi_{n}=\lim _{n \rightarrow \infty}\left[\mu_{n} M^{*} \sup _{p \in F(T)} \phi\left(p, x_{n}\right)+v_{n}\right]=0 .
$$

(IV) Now we prove $p^{\prime \prime} \in F(T)$.

Since $x_{n+1} \in C_{n+1}$ and $\alpha_{n} \rightarrow 0$, it follows from (3) and (4) that

$$
\sup _{t \geq 0} \phi\left(x_{n+1}, y_{n, t}\right) \leq \alpha_{n} \phi\left(x_{n+1}, x_{1}\right)+\left(1-\alpha_{n}\right) \phi\left(x_{n+1}, x_{n}\right)+\xi_{n} \rightarrow 0 \quad \text { as } n \rightarrow \infty .
$$

Since $x_{n} \rightarrow p^{*}$, by Lemma 2.2, for each $t \geq 0$, we have

$$
\lim _{n \rightarrow \infty} y_{n, t}=p^{*}
$$


Since $x_{n}$ is bounded, and $\mathbf{T}=\{T(t), t \geq 0\}$ is a total quasi- $\phi$-asymptotically nonexpansive semigroup with sequence $\mu_{n}, v_{n}, p \in F(T)$, we have

$$
\phi\left(p, T^{n}(t) x\right) \leq \phi(p, x)+\mu_{n} \psi(\phi(p, x))+v_{n} \leq \phi(p, x)+\mu_{n} M^{\prime \prime} \phi(p, x)+v_{n} .
$$

This implies that $\left\{T^{n}(t) x_{n}\right\}_{t \geq 0}$ is uniformly bounded. Since for each $t \geq 0$,

$$
\begin{aligned}
\left\|\omega_{n, t}\right\| & =\left\|J^{-1}\left(\beta_{n} J x_{n}+\left(1-\beta_{n}\right) J T^{n}(t) x_{n}\right)\right\| \\
& \leq \beta_{n}\left\|x_{n}\right\|+\left(1-\beta_{n}\right)\left\|T^{n}(t) x_{n}\right\| \\
& \leq \max \left\{\left\|x_{n}\right\|,\left\|T^{n}(t) x_{n}\right\|\right\} .
\end{aligned}
$$

This implies that $\left\{\omega_{n, t}\right\}, t \geq 0$ is also uniformly bounded. Since $\alpha_{n} \rightarrow 0$, from (3) we have

$$
\lim _{n \rightarrow \infty}\left\|J y_{n, t}-J \omega_{n, t}\right\|=\lim _{n \rightarrow \infty} \alpha_{n}\left\|J x_{1}-J \omega_{n, t}\right\|=0, \quad t \geq 0 .
$$

Since $E$ is uniformly smooth, $J^{-1}$ is uniformly continuous on each bounded subset of $E^{*}$, it follows from (5) and (6) that

$$
\lim _{n \rightarrow \infty} \omega_{n, t}=p^{*}, \quad \forall t \geq 0 .
$$

Since $x_{n} \rightarrow p^{*}$ and $J$ is uniformly continuous on each bounded subset of $E$, we have $J x_{n} \rightarrow$ $J p^{*}$, and for each $t \geq 0$,

$$
\begin{aligned}
0 & =\lim _{n \rightarrow \infty}\left\|J \omega_{n, t}-J p^{*}\right\|=\lim _{n \rightarrow \infty}\left\|\beta_{n} J x_{n}+\left(1-\beta_{n}\right) J T^{n}(t) x_{n}-J p^{*}\right\| \\
& =\lim _{n \rightarrow \infty}\left\|\beta_{n}\left(J x_{n}-J p^{*}\right)+\left(1-\beta_{n}\right)\left(J T^{n}(t) x_{n}-J p^{*}\right)\right\| \\
& =\lim _{n \rightarrow \infty}\left(1-\beta_{n}\right)\left\|\left(J T^{n}(t) x_{n}-J p^{*}\right)\right\| .
\end{aligned}
$$

By condition $0<\liminf _{n \rightarrow \infty} \beta_{n}<\lim \sup _{n \rightarrow \infty} \beta_{n}<1$, we have that

$$
\lim _{n \rightarrow \infty}\left\|J T^{n}(t) x_{n}-J p^{*}\right\|=0, \quad \text { uniformly for } t \geq 0
$$

Since $J$ is uniformly continuous, this shows that $\lim _{n \rightarrow \infty} T^{n}(t) x_{n}=p^{*}=0$ uniformly for $t \geq 0$. Again by the assumptions that the semigroup $\mathbf{T}:=\{T(t): t \geq 0\}$ is closed and uniformly $L$-Lipschitzian, we have

$$
\begin{aligned}
& \left\|T^{n+1}(t) x_{n}-T^{n}(t) x_{n}\right\| \\
& \quad \leq\left\|T^{n+1}(t) x_{n}-T^{n+1}(t) x_{n+1}\right\|+\left\|T^{n+1}(t) x_{n+1}-x_{n+1}\right\|+\left\|x_{n+1}-x_{n}\right\|+\left\|x_{n}-T^{n}(t) x_{n}\right\| \\
& \quad \leq(L(t)+1)\left\|x_{n+1}-x_{n}\right\|+\left\|T^{n+1}(t) x_{n+1}-x_{n+1}\right\|+\left\|x_{n}-T^{n}(t) x_{n}\right\| .
\end{aligned}
$$

By $\lim _{n \rightarrow \infty} T^{n}(t) x_{n}=p^{\prime \prime}$ uniformly for $t \geq 0, x_{n} \rightarrow p^{\prime \prime}$ and $L(t)$ is a bounded and measurable function, and from (7) we have that

$$
\lim _{n \rightarrow \infty}\left\|T^{n+1}(t) x_{n}-T^{n}(t) x_{n}\right\|=0 \quad \text { uniformly for } t \geq 0,
$$


and

$$
\lim _{n \rightarrow \infty} T^{n+1}(t) x_{n}=p^{*} \quad \text { uniformly for } t \geq 0 \text {, }
$$

so we get

$$
\lim _{n \rightarrow \infty} T(t) T^{n}(t) x_{n}=p^{*} \quad \text { uniformly for } t \geq 0 .
$$

By virtue of the closeness of semigroup $\mathbf{T}$, we have that $T(t) p^{*}=p^{*}$, i.e., $p^{*} \in F(T(t))$. By the arbitrariness of $t \geq 0$, we have $p^{*} \in F(T)=\bigcap_{t \geq 0} F(T(t))$.

(V) Finally, we prove $x_{n} \rightarrow p^{*}=\Pi_{F(T)} x_{1}$.

Let $\omega=\Pi_{F(T)} x_{1}$. Since $\omega \in F(T) \subset C_{n}$ and $x_{n}=\Pi_{C_{n}} x_{1}$, we get $\phi\left(x_{n}, x_{1}\right) \leq \phi\left(\omega, x_{1}\right), n \geq 1$. This implies that

$$
\phi\left(p^{*}, x_{1}\right)=\lim _{n \rightarrow \infty} \phi\left(x_{n}, x_{1}\right) \leq \phi\left(\omega, x_{1}\right) .
$$

In view of the definition of $\Pi_{F(T)} x_{1}$, from (8), we have $p^{*}=\omega$. Therefore, $x_{n} \rightarrow p^{*}=\Pi_{F(T)} x_{1}$. This completes the proof of Theorem 3.1.

\section{Competing interests}

The authors declare that they have no competing interests.

\section{Authors' contributions}

All the authors contributed equally to the writing of the present article. And they also read and approved the final manuscript.

\section{Author details}

'Department of Mathematics, Yibin University, Yibin, Sichuan, 644000, China. ${ }^{2}$ College of Statistics and Mathematics, Yunnan University of Finance and Economics, Kunming, Yunnan, 650221, China.

\section{Acknowledgements}

This work was supported by National Research Foundation of Yibin University (No. 2011B07) and by Scientific Research Fund Project of Sichuan Provincial Education Department (No. 12ZB345 and No. 11ZA172).

Received: 8 May 2012 Accepted: 22 August 2012 Published: 5 September 2012

\section{References}

1. Alber, $\mathrm{Yl}$, Chidume, $\mathrm{CE}$, Zegeye, $\mathrm{H}$ : Approximating fixed point of total asymptotically nonexpansive mappings. Fixed Point Theory Appl. 2006, Article ID 10673 (2006)

2. Chidume, CE, Ofoedu, EU: Approximation of common fixed points for finite families of total asymptotically nonexpansive mappings. J. Math. Anal. Appl. 333(1), 128-141 (2007)

3. Chidume, CE, Ofoedu, EU: A new iteration process for approximation of common fixed points for finite families of total asymptotically nonexpansive mappings. Int. J. Math. Math. Sci. 2009, Article ID 615107 (2009). doi:10.1155/2009/615107

4. Chang, S, Kim, JK, Joseph Lee, HW, Chan, CK: A generalization and improvement of Chidume theorems for total asymptotically nonexpansive mappings in Banach spaces. J. Inequal. Appl. 2012, 37 (2012). doi:10.1186/1029-242X-2012-37

5. Chang, S, Chan, CK, Joseph Lee, HW: Modified block iterative algorithm for Quasi- $\phi$-asymptotically nonexpansive mappings and equilibrium problem in Banach spaces. Appl. Math. Comput. 217, 7520-7530 (2011)

6. Qin, X, Cho, SY, Kang, SM: On hybrid projection methods for asymptotically quasi- $\phi$-nonexpansive mappings. Appl. Math. Comput. 215(11), 3874-3883 (2010)

7. Saewan, S, Kumam, P: Modified hybrid block iterative algorithm for convex feasibility problems and generalized equilibrium problems for uniformly quasi- $\phi$-asymptotically nonexpansive mappings. Abstr. Appl. Anal. 2010, 22 (2010). doi:10.1155/2010/357120

8. Chang, S, Wanga, L, Tang, Y-K, Wanga, B, Qin, L-J: Strong convergence theorems for a countable family of quasi- $\phi$-asymptotically nonexpansive nonself mappings. Appl. Math. Comput. 218, 7864-7870 (2012)

9. Qin, X, Huang, S, Wang, T: On the convergence of hybrid projection algorithms for asymptotically quasi- $\phi$-nonexpansive mappings. Comput. Math. Appl. 61(4), 851-859 (2011) 
10. Chang, S, Joseph Lee, HW, Chan, CK, Zhang, WB: A modified Halpern type iterative algorithm for total quasi- $\phi$-asymptotically nonexpansive mappings with applications. Appl. Math. Comput. 218(11), 6489-6497 (2012)

11. Wang, X, Chang, S, Wang, L, Tang, Y-K, Xu, YG: Strong convergence theorems for nonlinear operator equations with total quasi- $\phi$-asymptotically nonexpansive mappings and applications. Fixed Point Theory Appl. 2012, 34 (2012) doi:10.1186/1687-1812-2012-34

12. Zuo, P, Chang, S, Liu, M: On a hybrid algorithm for a family of total quasi- $\phi$-asymptotically nonexpansive mappings in Banach spaces. Fixed Point Theory Appl. 2012, 70 (2012). doi:10.1186/1687-1812-2012-70

13. Ye, J, Huang, J: Strong convergence theorems for fixed point problems and generalized equilibrium problems of three relatively quasi-nonexpansive mappings in Banach spaces. J. Math. Comput. Sci. 1, 1-18 (2011)

14. Kim, JK: Strong convergence theorems by hybrid projection methods for equilibrium problems and fixed point problems of the asymptotically quasi- $\phi$-nonexpansive mappings. Fixed Point Theory Appl. 2011,10 (2011)

15. Saewan, S, Kumam, P: The shrinking projection method for solving generalized equilibrium problems and common fixed points for asymptotically quasi- $\phi$-nonexpansive mappings. Fixed Point Theory Appl. 2011, 9 (2011)

16. Alber, YI: Metric and generalized projection operators in Banach spaces: properties and applications. In: Kartosator, AG (ed.) Theory and Applications of Nonlinear Operators of Accretive and Monotone Type, pp. 15-50. Dekker, New York (1996)

17. Chang, SS, Joseph Lee, HW, Chan, CK: Convergence theorem of common fixed point for asymptotically nonexpansive semigroups in Banach spaces. Appl. Math. Comput. 212,60-65 (2009)

18. Zegeye, H, Shahzadb, N, Damana, OA: Strong convergence theorems for a semigroup of asymptotically nonexpansive mappings. Math. Comput. Model. 54, 2077-2086 (2011)

19. Chang, S, Wang, L, Tang, Y-K, Zao, Y-H, Wang, B: Strong convergence theorems of quasi- $\phi$-asymptotically nonexpansive semi-groups in Banach spaces. Fixed Point Theory Appl. 2012, 15 (2012). doi:10.1186/1687-1812-2012-15

doi:10.1186/1687-1812-2012-142

Cite this article as: Quan et al.: Strong convergence for total quasi- $\phi$-asymptotically nonexpansive semigroups in Banach spaces. Fixed Point Theory and Applications 2012 2012:142.

\section{Submit your manuscript to a SpringerOpen ${ }^{\circ}$ journal and benefit from:}

- Convenient online submission

Rigorous peer review

- Immediate publication on acceptance

- Open access: articles freely available online

- High visibility within the field

- Retaining the copyright to your article 